Primljen: 12. februara 2021.

Prihvaćen: 3. aprila 2021.

Nevenka S. Balanesković ${ }^{1}$

https://doi.org/10.46630/phm.13.2021.59

Univerzitet u Nišu

Filozofski fakultet

Departman za francuski jezik i književnost

\title{
PUTOVANJE ULEVO: PREPEVI PESAMA VIKTORA IGOA IZ ZBIRKE KONTEMPLACIJE
}

Klatno hita da dosegne krajnju tačku u svom otklonu, i baš tu se predomišlja i poletno stremi ka svojoj suprotnosti, ka drugoj krajnosti. Klatno ne bi ni bilo klatno da nema leve i desne strane. Ako bi kretanje prestalo, ono više ne bi merilo vreme. Tako je i sa poetikom kroz epohe: strana razuma i strana srca, večno nezadovoljstvo polovičnošću i večno traganje za celovitošću. Strana razuma gradi u ovostranoj stvarnosti kule i gradove, drži se strogosti, simetrije, pročišćenosti, svedenosti, uzvišenosti, veličanstvenosti pod ovim suncem. A onda se strana srca pobuni, ugrejana onostranom intuitivnošću, nedokučivošću, nejasnoćom, neobjašnjivošću, a ipak od ljudske duše neodvojivom i bliskom pararealnošću. Pa srce hoda po ruševinama razuma, a razum se podiže iznad izmaglica duše, jedno drugo kritikujući i ne shvatajući, jedno od drugog zauvek se opraštajući i opet neminovno srećući u centralnoj tački putanje klatna.

U ovoj maloj „zbirci” pesama koje su sabrane prema kriterijumu klatna na srčanoj strani, našle su se pesme iz doba romantizma. Izbor je pao na njih po nekoj tajnoj vezi između pesnika i prevodioca. To su pesme Viktora Igoa koje on naziva „sećanjima jedne duše”. Duša ne pohranjuje svoja sećanja bilo gde; ona ima za njih svoj hram (templum-contemplatio), pa je zato Viktor Igo svoju zbirku od stotinu pedeset šest pesama, razvrstanih u šest knjiga, nazvao Kontemplacije. Ta zbirka predstavlja svojevrsni eksperimentalni žanr koji bi se mogao nazvati „autobiografijom u stihu”. U tom hramu pesnikova duša duboko promišlja o svom životu i u nekoj vrsti unutrašnje vizije otkriva svoj put, svoj smisao, seže daleko na levu stranu transcedentalnog „prinoseći na žrtvu”, kao u svakom hramu, najpotresniji događaj iz svoga života, tragičnu

1 n.balaneskovic-16294@filfak.ni.ac.rs 
smrt svoje kćeri, Leopoldine. ${ }^{2}$ Deleći svoj život nadvoje, na sunčanu i mračnu stranu, na sreću i nesreću, ali i na razum i mudrost koja premašuje razum, na ovde i tamo, Igo prelazi ambis našavši most. I tako će u Predgovoru te svoje zbirke pisati ovako: „Šta su to Kontemplacije? To je ono što bi se moglo nazvati, ako ta reč ne bi bila pretenciozna, Memoarima jedne duše. To su, u stvari, svi utisci, sve uspomene, sve stvarnosti, sve neuhvatljive seni, nasmejane ili ucveljene koje može sadržati svest, koje se vraćaju ili kojih se sećamo, zrak po zrak, uzdah po uzdah i pomešane su u istom tmurnom oblaku. To je ljudski život koji kreće od zagonetke kolevke i okončava se zagonetkom kovčega: to je duh koji hoda od žara do žara ostavljajući za sobom mladost, ljubav, zanos, borbu, očaj, i koji se zaustavlja izgubljen 'na rubu beskonačnosti'. Počinje jednim osmehom, nastavlja se jecanjem i završava se trubom ambisa. Jedna sudbina je opisivana ovde iz dana u dan. Je li to dakle život jednog čoveka? Da, i život drugih ljudi takođe. Niko od nas nema tu čast da ima život koji bi bio samo njegov. Moj život je i vaš, vaš život je moj, vi živite to što ja živim; sudbina je jedna."3 (HUGO, 1856: 8-9)

U ovoj našoj nevelikoj zbirci prepeva ići ćemo „od žara do žara” i preći most izgrađen od prepeva-prvenaca, most između našeg i pesnikovog jezika, sporazumevaćemo se $s$ njim $u$ istom hramu, duboko promišljajući o svemu o čemu je i on promišljao, žurno hodajući kroz život „očiju uprtih u svoje misli”. Uzeti malo tuđega žara i ogrejati se na njemu, to je iskustvo čitaoca. Onaj koji se usudi da pokuša ponešto od toga da prenese na svoj jezik, može da pronađe još više topline, ali postoji rizik i da se opeče. Naš jezik je prelep, veoma bogat i precizan, može biti zato što smo u pometnji jezika u Vavilonskoj kuli prigrabili poprilično bogatstvo. Melodičnost našeg jezika se, među muzičarima, upoređuje sa melodičnošću italijanskog jezika i posle njega smatra se najpevljivijim jezikom ili, kako to veliki poljski pesnik Adam Mickjevič kaže, srpski je italijanski među slovenskim jezicima, a najveći „slobodnjak” srpskoga jezika, koji se nijednim rečnikom niti pravopisom živ ne da u puta i verige okovati, Matija Bećković, poredi srpski sa našom nevidljivom, nepodeljenom i još

2 O okolnostima objavljivanja zbirke Kontemplacije i njenoj strukturi, opširnije v. BJELIĆ 2019: 299 - 307.

3 «Qu'est-ce que les Contemplations ? C'est ce qu'on pourrait appeler, si le mot n'avait quelque prétention, les Mémoires d'une âme. Ce sont, en effet, toutes les impressions, tous les souvenirs, toutes les réalités, tous les fantômes vagues, riants ou funèbres, que peut contenir une conscience, revenus et rappelés, rayon à rayon, soupir à soupir, et mêlés dans la même nuée sombre. C'est l'existence humaine sortant de l'énigme du berceau et aboutissant à l'énigme du cercueil ; c'est un esprit qui marche de lueur en lueur en laissant derrière lui la jeunesse, l'amour, l'illusion, le combat, le désespoir, et qui s'arrête éperdu 'au bord de l'infini'. Cela commence par un sourire, continue par un sanglot, et finit par un bruit du clairon de l'abîme.

Une destinée est écrite là jour à jour. Est-ce donc la vie d'un homme ? Oui, et la vie des autres hommes aussi. Nul de nous n'a l'honneur d'avoir une vie qui soit à lui. Ma vie est la vôtre, votre vie est la mienne, vous vivez ce que je vis ; la destinée est une. »(HUGO, 1856: 8-9). 
nerazorenom crkvom. Srpski jezik predivno zvuči pretočen u stihove; ritmičan je zahvaljujući raznovrsnim akcentima i ima mnogo mogućnosti za rimu. Ova pohvala našem jeziku može da zvuči i kao izvinjenje nekoga koji je svoj život posvetio drugim jezicima, ali, naravno, to jeste samo jednim svojim majušnim delom.

Bez sumnje, čitati pesmu na originalnom jeziku velika je prednost, jer svaki, ma i najbolji prevod i prepev ne može biti u svemu istovetan sa originalom. Prevodilac je tu na mukama između vernosti i iskušenja da prekorači granice svoje odgovornosti i da i on sam postane pesnik, a svi pesnici teže za slobodom. U odnosu na pesnika, on je u mnogo boljem, tj. lakšem položaju: pred njim je sve otkriveno, on ulazi u carstvo slika, on ne čuje više reči, nego gleda slike, a gledajući slike, dolazi u iskušenje da ih pa makar i malo drugačije opiše, da nađe neki svoj leksički ekvivalent, da prividno ostane veran, a da $\mathrm{u}$ suštini ostane slobodan. Proživevši pesmu i proživevši je zajedno s pesnikom, on budi u sebi sopstvena iskustva, biva podstaknut da to prenese na svoj jezik. I tako otvara škrinju onog svog blaga koje mu je zapalo u deo kada se delio plen iz Vavilonske kule. Sa pregratka u njoj gde je pohranjen pesnički registar njegovog jezika, veoma se retko skidaju katanci, zato što to blago ne sme da se arči svakoga dana, već samo na svetkovine i praznike životnih radosti i amanete na rastancima. A kad se prevod odene u stajaće ruho, kad stane pred nas onako sav gizdav i svečan, valja ga zategnuti, prikupiti i upristojiti metrom i rimom, skinuti sve suvišno, u zadnji čas se setiti još nečeg, boljeg i lepšeg i kudikamo prikladnijeg. Pa kad ga tako udesimo, onda, hajd' u svet! Idi, diči se, kočoperi se, nek' vide kako si lep!

Umeju pesnici da stave prevodioca na velike muke, pred teške, skoro nerešive zadatke. To je slučaj onda kada se pesnici poigravaju svojim jezikom. Na primer, u poslednjoj strofi pesme Bubamara, javila su se dva problema: ime te bube na francuskom i na srpskom i jedan par reči istog korena, a sasvim drugačijeg značenja. Bubamara znači buba Marije Bogorodice (moguće da je to došlo iz nemačkog jezika, gde se bubamara kaže Marienkäfer i ima isto značenje - Marijina buba), a na francuskom jeziku la bête à bon Dieu, tj. životinjica dobroga Boga. Drugi naziv je la coccinelle, kako je pesnik izabrao da je nazove u naslovu pesme. Naziv la bête, životinjica pojavljuje se u poslednjoj strofi, da bi tu parirao jednoj drugoj reči, reči bêtise, koja znači ludost, glupost, a s namerom da opiše mladića, još skoro dečaka, koji se nije snašao u prilici da dobije poljubac kada je zamoljen da sa vrata devojke, nešto starije od njega, skine bubamaru. (Za propuštenim prilikama žaliće Igoov lirski subjekat u još nekim pesmama.) Tako je u prevodu izabran ljubak par izraza koji se čak i rimuje, buba u travi i buba u glavi.

Prevodilac mora da zna da broji na prste, a da se pritom ne zbuni koliko puta je prošao koju ruku, kad već nema dvanaest, četrnaest ili više pr- 
stiju. Viktor Igo je svoje pesme uglavnom pisao stihom od dvanaest slogova, koji se zove aleksandrinac. Najlepše je ostati pri istom broju slogova, ako je to moguće, ali ne po cenu toga da blaga u našoj škrinji ostanu neiskorišćena. To bi značilo zbog forme (koja u pesmama nije nimalo zanemarljiva, naprotiv) ostati uskraćen za brojne lepote samog sadržaja onih slika koje ostaju pred našim očima neprenesene na odgovarajući način, samo zato što moramo da odsečemo dva sloga. Tako nešto smatramo neopravdanim. Poneki stih bi mogao podneti tu stegu, ali već naredni ima toliko toga da kaže, da mu je i četrnaest nedovoljno, ali uz malo reda, uz malo preturanja po našoj škrinji, nevolja se da rešiti. Namera nije da se upuštamo u bilo kakve stručne rasprave o prevođenju, ali nije zgoreg citirati ovde Nikolu Bartolina (2004: 563-564) : „Čitalac ove knjige će svakako uočiti da se moji prevodi Ifigenije i Atalije razlikuju od ostalih prevoda u ovoj knjizi po stihu u kojemu sam ih preveo, a to je četrnaesterac. Naime, još dok sam prevodio Bereniku i Mitridata, stekao sam uzisak da naš trohejski dvanaesterac nije najbolje rešenje za francuski aleksandrinac - utisak koji je kasnije samo potvrđen dok sam prevodio dela Igoa, Bodlera i Apolinera. Naš je dvanaesterac kraći od aleksandrinca, kako zbog činjenice da su francuske reči u proseku kraće od naših, tako i zbog prividno nepostojećeg dodatnog - trinaestog - sloga što ga u aleksandrincu predstavlja 'nemo e' u okviru takozvane ženske rime. (Pri recitovanju, kao i pri pevanju pesama, to se nemo e, uostalom, izgovara, tako da postaje 'muklo e'.) [...] Nevolja je u tome što se ni u najboljim prevodima ne može otkloniti monotonija našeg trohejskog dvanaesterca."

Prava lepota prepeva jesu rime. No, ako se tu ne pazi na vrstu reči, na to da li je reč gramatička ili leksička, sve može otići u propast ili se uzdići do veoma prijatnog doživljaja. Rima je luksuz koji sebi može da priušti samo poezija (u užem smislu reči, u smislu lirike), za razliku od proze, koja ima svoje lepote. Rima zato ne sme biti jeftina, petparačka, nego neočekivana, važna, naravno, kad god je to moguće. Neki veliki pesnici, kao, recimo, Gete u pesmi An Schwager Chronos (Prikanu Hronosu, u kojoj Hronosa, boga vremena, predstavlja kao kočijaša kojem on dovikuje naređenja kako da vozi kočije i tera konja), dopuštaju sebi da potpuno izostave rimu i da, umesto te plemenite i prefinjene osobenosti, koriste neke druge mogućnosti, kao što su ritam, izbor glasova itd. Igo je više voleo da ostane veran rimi i pravo je zadovoljstvo imati takvo bogatstvo u stihovima.

Onda kada „sećanja jedne duše” postaju „sećanja svake duše” koja ih bude čitala prihvatajući uzbudljivo putovanje na klatnu „ulevo”, otkrićemo bliskost pesnikovog iskustva i vremenska udaljenost neće biti nikakva prepreka. Odahnućemo pri spoznaji da je još neko ljudsko biće osetilo, propatilo i preživelo ista ili slična iskustva kao naša sopstvena. Osećanje pripadnosti i srodnosti donosi utehu i spokoj. 


\section{Citirana literatura}

BJELIĆ, Nikola. « Le motif du pont dans la poésie française (Hugo, Rimbaud, Apollinaire)». In : Facta Univesitatis, Series : Linguistics and Literature. Vol. 17. No 2. [Réd. Nikola Bjelić et Ivan Jovanović. Réd. en chef. Violeta Stojičićc]. Niš : Université de Niš. 299-307. Dostupno na: http://casopisi.junis.ni.ac.rs/ index.php/FULingLit/article/vie w/5414/3414

HUGO, 1856: Hugo, Victor. Les Contemplations. Paris: Le Livre de poche, 1856, https://www.argotheme.com/hugo_contemplations.pdf [21. 12. 2020]

BARTOLINO, 2004: Bartolino, Nikola. Pogovor u: Ž. Rasin, Tragedije, Beograd: PAIDEIA,

str. 559-566.

\section{Izvori}

HUGO, 1856: Hugo, Victor. Les Contemplations. Paris: Le Livre de poche, 1856. https://www.argotheme.com/hugo_contemplations.pdf [21. 12. 2020]

\section{LIVRE PREMIER / PRVA KNJIGA}

XV.

\section{LA COCCINELLE}

Elle me dit : "Quelque chose Me tourmente. » Et japerçus Son cou de neige, et, dessus, Un petit insecte rose.

J’aurais dû - mais, sage ou fou, À seize ans, on est farouche, Voir le baiser sur sa bouche Plus que l'insecte à son cou.

On eût dit un coquillage ;

Dos rose et taché de noir.

Les fauvettes pour nous voir

Se penchaient dans le feuillage.

Sa bouche fraîche était là :

Je me courbai sur la belle,

Et je pris la coccinelle;

Mais le baiser s'envola.

«Fils, apprends comme on me nomme», 
Dit l'insecte du ciel bleu,

"Les bêtes sont au bon Dieu;

Mais la bêtise est à l'homme. »

\section{BUBAMARA}

Ona mi reče: „Šta me golica?”

Tad spazih belji od snega bela

Vrat njezin, a na njega je sela

Crvene boje mala bubica.

Trebaše - uman il' lud, ko zna tu?

Sa šesnaest, narav nam je pusta, -

Poljubit' je radije u usta

Negoli gledat' bubu na vratu.

Bila je poput školjke na hridi

Crvena leđa, tačkice crne.

Naginje se da lišće razgrne,

Slavuja jato, tek da nas vidi.

Usne joj rujne bejahu preče

Nadvijen nad lepojkom kad beh,

Ali ja joj bubamaru uzeh

I zato poljubac taj uteče.

„Čuj momče, ime moje ne kvari”

Buba mi sa neba plava priča,

„Bube u travi su Božja bića;

A bube u glavi, ljudske stvari.”

XIX.

\section{VIEILLE CHANSON DU JEUNE TEMPS}

Je ne songeais pas à Rose ;

Rose au bois vint avec moi ;

Nous parlions de quelque chose,

Mais je ne sais plus de quoi.

J'étais froid comme les marbres ;

Je marchais à pas distraits ;

Je parlais des fleurs, des arbres;

Son œil semblait dire : "Après ? » 
La rosée offrait ses perles,

Le taillis ses parasols ;

J'allais ; jécoutais les merles,

Et Rose les rossignols.

Moi, seize ans, et l'air morose ;

Elle, vingt ; ses yeux brillaient.

Les rossignols chantaient Rose,

Et les merles me sifflaient.

Rose, droite sur ses hanches,

Leva son beau bras tremblant

Pour prendre une mûre aux branches ;

Je ne vis pas son bras blanc.

Une eau courait, fraîche et creuse

Sur les mousses de velours ;

Et la nature amoureuse

Dormait dans les grands bois sourds.

Rose défit sa chaussure,

Et mit, d'un air ingénu,

Son petit pied dans l'eau pure ;

Je ne vis pas son pied nu.

Je ne savais que lui dire ;

Je la suivais dans le bois,

La voyant parfois sourire

Et soupirer quelquefois.

Je ne vis qu'elle était belle

Qu'en sortant des grands bois sourds.

«Soit; n’y pensons plus!» dit-elle.

Depuis, j’y pense toujours.

\section{STARA PESMA O MLADOSTI}

O Rozi misli moje ne biše

Kada u šumu krenuli besmo;

$\mathrm{Da}$, o nečemu pričali jesmo,

samo o čemu, to ne znam više.

Bio sam poput mramora hladan,

Koraci tamo i amo kreću

Pričao sam o drveću, cveću; 
„A potom?” pita pogled njen jadan.

U šumarku suncobrani stoje,

A perle sjajne nudila rosa;

Išo sam dalje i slušo kosa,

A Roza slavuja kako poje.

Ja, šesnaest, naizgled sumoran;

Ona, dvadeset; očiju sjajnih.

Rozi pevahu slavuji bajni,

A meni zviždaše kosić oran.

Roza, držeć' se pravo u telu, Podiže lepu drhtavu ruku Da si ubere kupinu mrku;

A ja ne videh tu ruku belu.

I potok bistri vrtloge prosu

Po mahovini kao po plišu;

Stvorenja, tvari, ljubavlju dišu,

Snovima u tihoj šumi što su.

Roza izu cipelicu prosto

I stavi, onako slatko i milo, Maleno stopalo vodi u krilo;

A ja ne videh stopalo boso.

Nisam ni znao šta ću joj reći;

Samo sam za njom kroz šumu išo,

Pazeći kad bi osmeh naišo

A katkada uzdah joj motreći.

Da beše lepa, videh tek tada

kad iz te šume velike kroči.

„Ne mislimo o tom' više!", sroči.

Al' o tom' mislim stalno otada.

XXI.

Elle était déchaussée, elle était décoiffée,

Assise, les pieds nus, parmi les joncs penchants ;

Moi qui passais par là, je crus voir une fée,

Et je lui dis : Veux-tu t'en venir dans les champs?

Elle me regarda de ce regard suprême 
Qui reste à la beauté quand nous en triomphons,

Et je lui dis : Veux-tu, c'est le mois où l'on aime,

Veux-tu nous en aller sous les arbres profonds?

Elle essuya ses pieds à l'herbe de la rive ;

Elle me regarda pour la seconde fois,

Et la belle folâtre alors devint pensive.

Oh ! comme les oiseaux chantaient au fond des bois!

Comme l'eau caressait doucement le rivage!

Je vis venir à moi, dans les grands roseaux verts,

La belle fille heureuse, effarée et sauvage,

Ses cheveux dans ses yeux, et riant au travers.

Ona beše izuvena, kosa raspletena bila,

Sedela je bosonoga u trščaru lelujavu,

A meni se kao vila u prolazu pričinila,

Pa joj rekoh: Hoćeš sa mnom po poljima gazit’ travu?

Pogleda me smelo, ohole joj oči k meni streme

Da počinu zadovoljno u trijumfu nad lepotom.

Ja joj opet rekoh: Hajde, ljubavi je ovo vreme,

Hoćeš sa mnom pod drveće gorostasno ići potom?

Stopala joj bilje na obali nežno obrisalo,

Pa ponovo kriomice poglednu me njeno oko,

Šaljivica lepa zastade i zamisli se malo.

O, kako su zapevale ptice u šumi duboko!

A kako li samo voda priobalje milovaše!

Ja je gledam: kroz trstike vitke k' meni ide, eno,

Lepotica, i plaha i srećna divljaka iz šaše,

To se meni smeši oko njeno kosom pokriveno.

XXIV.

Heureux l'homme, occupé de l'éternel destin,

Qui, tel qu'un voyageur qui part de grand matin,

Se réveille, l'esprit rempli de rêverie,

Et, dès l'aube du jour, se met à lire et prie !

À mesure qu'il lit, le jour vient lentement

Et se fait dans son âme ainsi qu'au firmament.

Il voit distinctement, à cette clarté blême,

Des choses dans sa chambre et d'autres en lui-même ;

Tout dort dans la maison; il est seul, il le croit ; 
Et, cependant, fermant leur bouche de leur doigt,

Derrière lui, tandis que l'extase l'enivre,

Les anges souriants se penchent sur son livre.

Srećan je koga sudba večna na miso prene, Koji k’o putnik zorom na put daleki krene, Probudiv se rano i duha što jošte sanja, Te dan dok sviće, on čita, moli se i klanja! I dok on tako čita, dan osvaja u hodu, Razdanjuje se duši k’o na nebeskom svodu. On sasvim jasno vidi plavetnilo dok bledi Stvari u svojoj sobi, stvari u samom sebi; Dok sve u kući spava, sam je, verujuć' sluti, No držeći prst na usta u znak da se ćuti, Nad njime su, dok on zanosom opijen biva, Anđeli s osmejkom nagnuti iznad tog štiva.

\section{LIVRE DEUXIÊME / DRUGA KNJIGA}

IV.

\section{CHANSON}

Si vous n'avez rien à me dire, Pourquoi venir auprès de moi ?

Pourquoi me faire ce sourire Qui tournerait la tête au roi ? Si vous n'avez rien à me dire, Pourquoi venir auprès de moi ?

Si vous n'avez rien à m’apprendre, Pourquoi me pressez-vous la main? Sur le rêve angélique et tendre, Auquel vous songez en chemin, Si vous n'avez rien à m'apprendre, Pourquoi me pressez-vous la main?

Si vous voulez que je m'en aille, Pourquoi passez-vous par ici ? Lorsque je vous vois, je tressaille :

C'est ma joie et c'est mon souci. Si vous voulez que je m'en aille, Pourquoi passez-vous par ici ?

\section{PESMA}

Ako mi nemate ništa reći, 
zašto ste uvek uz mene tako?

Zašto i čemu osmejak steći

što kralju um bi smutio lako?

Ako mi nemate ništa reći, zašto ste uvek uz mene tako?

Ako me nemate učit' čemu, zašto mi tako stišćete ruku?

O snu anđelskom i nežnom svemu

o kome misli se putem vuku, ako me namate učit' čemu, zašto mi tako stišćete ruku?

I ako biste da odem tako, što prolazite stalno ovuda? Kad Vas ugledam, trgnem se jako:

To mi je radost i zebnja huda.

I ako biste da odem tako, što prolazite stalno ovuda?

V.

\section{HIER AU SOIR}

Hier, le vent du soir, dont le souffle caresse, Nous apportait l'odeur des fleurs qui s'ouvrent tard ; La nuit tombait ; l'oiseau dormait dans lombre épaisse. Le printemps embaumait, moins que votre jeunesse ; Les astres rayonnaient, moins que votre regard.

Moi, je parlais tout bas. C'est l'heure solennelle Où lâme aime à chanter son hymne le plus doux. Voyant la nuit si pure, et vous voyant si belle, J'ai dit aux astres d'or : Versez le ciel sur elle! Et j'ai dit à vos yeux : Versez l'amour sur nous!

\section{SINOĆ}

Juče nam sutonski vetrić i dašak mileni donese miris cveća što otvara se kasno; noć pade i ptičica usnu u tamnoj seni. Opojna prolet, još većma Vaša mladost meni; sijahu zvezde, al' ne k’o oko Vaše jasno.

A ja govorih posve tiho. Svečan beše čas 
kad duša pevat' htede najslađu himnu svoju.

Videvši noć tako čistu, a tako lepu Vas, „Na nju prospite nebo!” rekoh zvezdanom roju, onda očima Vašim: „Prospite ljubav na nas!”

XVI.

L'hirondelle au printemps cherche les vieilles tours,

Débris où n'est plus l'homme, où la vie est toujours;

La fauvette en avril cherche, ô ma bien-aimée,

La forêt sombre et fraîche et lépaisse ramée,

La mousse, et, dans les nœuds des branches, les doux toits

Qu'en se superposant font les feuilles des bois.

Ainsi fait l'oiseau. Nous, nous cherchons, dans la ville,

Le coin désert, l'abri solitaire et tranquille,

Le seuil qui n’a pas d'yeux obliques et méchants,

La rue où les volets sont fermés; dans les champs,

Nous cherchons le sentier du pâtre et du poète ;

Dans les bois, la clairière inconnue et muette

Où le silence éteint les bruits lointains et sourds.

Loiseau cache son nid, nous cachons nos amours.

Lasta se u proleće na kuli staroj svija

U ruini gde ljudi nema, gde život tija.

Slavuj u aprilu traži, o voljena moja,

Tamni, prohladni čestar i listova bez broja, Mahovinu, u krošnji puno mekih krovova, Jedan nad drugim da su spleteni od listova.

To rade ptice. A mi u gradu da se bira

Kutak napušten i zaklon samoće i mira, dovratak gde nema očiju zla i nevolja, ulica zatvorenih kapaka, pa u polja da pronađemo stazu pesnika i pastira, u šumama proplanak skrovitosti i mira, gde tihnu zvuci daleki u gluve pokoje. Ptice skrivaju gnezdo, a mi ljubavi svoje.

XX.

\section{IL FAIT FROID}

L'hiver blanchit le dur chemin.

Tes jours aux méchants sont en proie.

La bise mord ta douce main ;

La haine souffle sur ta joie. 
La neige emplit le noir sillon. La lumière est diminuée... Ferme ta porte à l'aquilon!

Ferme ta vitre à la nuée!

Et puis laisse ton cœur ouvert! Le cœur, c'est la sainte fenêtre. Le soleil de brume est couvert; Mais Dieu va rayonner peut-être!

Doute du bonheur, fruit mortel ;

Doute de l'homme plein d'envie ;

Doute du prêtre et de l'autel ;

Mais crois à l'amour, ô ma vie !

Crois à l'amour, toujours entier, Toujours brillant sous tous les voiles!

À l'amour, tison du foyer !

À l’amour, rayon des étoiles !

Aime et ne désespère pas.

Dans ton âme où parfois je passe,

Où mes vers chuchotent tout bas,

Laisse chaque chose à sa place.

La fidélité sans ennui,

La paix des vertus élevées,

Et l'indulgence pour autrui,

Éponge des fautes lavées.

Dans ta pensée où tout est beau, Que rien ne tombe ou ne recule.

Fais de ton amour ton flambeau.

On séclaire de ce qui brûle.

À ces démons d'inimitié,

Oppose ta douceur sereine, Et reverse-leur en pitié

Tout ce qu'ils t'ont vomi de haine.

La haine, c'est l'hiver du cœur.

Plains-les ! mais garde ton courage.

Garde ton sourire vainqueur ;

Bel arc-en-ciel, sors de l'orage! 
Garde ton amour éternel.

L'hiver, l'astre éteint-il sa flamme?

Dieu ne retire rien du ciel ;

Ne retire rien de ton âme!

\section{HLADNO JE}

Zima zabeli trnoviti put.

Dani ti se od zlih napatiše.

Ruku nežnu ujeda vetar ljut,

A mržnja radosti tvoje briše.

Crne se brazde sad snegom pune.

Videlo ti sve slabije gori...

Zatvori vrata kad sever dune!

I za oblake prozor zatvori!

No otvoreno ostavi srce!

Srce je sveti prozor od kuće.

Da, magle mogu prekriti sunce

Al' Bogu je zasjati moguće!

Sumnjaj u sreću, to je smrtna stvar,

Sumnjaj kad koga zavist preotme,

Sumnjaj u popa, pa i u oltar

Al' veruj u ljubav, moj živote!

Veruj u ljubav da nije lomna, Velova mnogih nestaće mraka!

U ljubav što je ugarak doma!

U ljubav što je zvezdice zraka!

Voli, očaju nemoj se dati.

U tvojoj duši gde prođem često,

Stihove moje gde šapat prati

Neka sve dobije svoje mesto.

Vernost dosadna da ti ne bude,

Vrlinom samo u mir se uđe,

Popustljiv budi za druge ljude,

Obriši zato pogreške tuđe.

Tvoje nek' misli lepote nude

Nek' ništa ne padne, ne posrne. 
Nek' ljubav tvoja baklja ti bude.

Svetli nam ono što ne utrne.

Dušman k’o demon kada navali

Smirenu milost ne daj da truje

Umesto toga ti se sažali

Svakom što mržnjom po tebi bljuje.

Mržnja u srcu je hladna zima.

Žali ih! hrabrost nek' te okuje.

Osmeh pripada pobednicima;

Predivna duga posle oluje!

Sačuvati ljubav večnu treba.

Zimi zar zvezda plam svoj ugasi?

Bog ništa ne sklanja sa svog neba;

Nit sklanja što dušu tvoju krasi!

\section{XXI.}

Il lui disait : « Vois-tu, si tous deux nous pouvions,

«Lâme pleine de foi, le cour plein de rayons,

« Ivres de douce extase et de mélancolie,

« Rompre les mille nœuds dont la ville nous lie;

«Si nous pouvions quitter ce Paris triste et fou,

« Nous fuirions; nous irions quelque part, n'importe où,

«Chercher loin des vains bruits, loin des haines jalouses,

«Un coin où aurions des arbres, des pelouses,

«Une maison petite avec des fleurs, un peu

«De solitude, un peu de silence, un ciel bleu,

« La chanson d'un oiseau qui sur le toit se pose,

«De l'ombre ; - et quel besoin avons-nous d'autre chose?»

„Znaš”, on joj reče, „kada bismo mogli oboje

$\mathrm{S}$ verom u duši i srcem ozareno što je,

Opijeni ushitom slatkim, tugom što steže,

Pokidat' hiljadu veza kojim' nas grad veže;

Kad bismo mogli napustit' Pariz, tužan i lud,

Da pobegnemo i odemo nekud, bilo kud,

Daleko od mržnje, ljubomore, buke tašte,

Kutak da nađemo s' drvećem i s' malo bašte,

Kućerak sa cvećem i malo samoće samo,

Malo tišine i parče plavog neba tamo,

Pesmu ptice što bi na krov naš sedela dugo, 
I senicu - šta bi nam od tog' trebalo drugo?

\section{LIVRE QUATRIÈME / ČETVRTA KNJIGA}

IV.

Oh! je fus comme fou dans le premier moment, Hélas ! et je pleurai trois jours amèrement.

Vous tous à qui Dieu prit votre chère espérance,

Pères, mères, dont l'âme a souffert ma souffrance,

Tout ce que jéprouvais, l’avez-vous éprouvé ?

Je voulais me briser le front sur le pavé ;

Puis je me révoltais, et, par moments, terrible, Je fixais mes regards sur cette chose horrible, Et je n'y croyais pas, et je mécriais : Non!

- Est-ce que Dieu permet de ces malheurs sans nom

Qui font que dans le cœur le désespoir se lève ? -

Il me semblait que tout nétait qu'un affreux rêve,

Qu'elle ne pouvait pas mavoir ainsi quitté,

Que je l’entendais rire en la chambre à côté,

Que cétait impossible enfin quelle fût morte,

Et que jallais la voir entrer par cette porte !

Oh ! que de fois j’ai dit : Silence ! elle a parlé !

Tenez! voici le bruit de sa main sur la clé !

Attendez ! elle vient ! laissez-moi, que jécoute !

Car elle est quelque part dans la maison sans doute!

Oh, ja bejah u tom prvom trenutku kao lud, avaj! I plakah tri dana gorko i uzalud.

Vi što Bog vam milenu nadu ne hte da vrati,

Očevi, majke, čija duša ko moja pati,

što ja iskusih, iskusiste li isto delo?

Htedoh o pločnik tada da smrskam svoje čelo;

A onda katkad žestoko pobuna se ote

Ni za trenut ne skidah pogled sa te strahote,

Niti verovah u nju, no kriknuh: Ne, to nije!

Zar Bog pušta ovu kob bezimenu da bije,

Čineć da srce tone u očajanja bezdan?

Sve mi se činjaše k’o da sanjam san užasan,

Nije mogla napustit' me tako, ne verujem,

Smeh njen tu u drugoj odaji kao da čujem,

Da je mrtva, ne, to naprosto nije moguće

Ja ću je videti na ova vrata kad uđe!

Oh! Kako kadikad rekoh: Tiho! Ona zbori! 
Stan'te! Evo, ključ će njenom rukom da otvori!

Čekajte! Ona ide! Ćutite, da čujem sam!

Tu je, u kući je negde, u to sam siguran!

\section{XIV.}

Demain, dès l'aube, à l'heure où blanchit la campagne,

Je partirai. Vois-tu, je sais que tu mattends.

J'irai par la forêt, j'irai par la montagne.

Je ne puis demeurer loin de toi plus longtemps.

Je marcherai les yeux fixés sur mes pensées,

Sans rien voir au dehors, sans entendre aucun bruit,

Seul, inconnu, le dos courbé, les mains croisées,

Triste, et le jour pour moi sera comme la nuit.

Je ne regarderai ni l'or du soir qui tombe,

Ni les voiles au loin descendant vers Harfleur,

Et, quand jarriverai, je mettrai sur ta tombe

Un bouquet de houx vert et de bruyère en fleur.

Sutra, zorom, kad se selo odene belinom, ja krećem. Vidiš li, znam da mene čekaš tamo, ići ću šumom, a potom ću ići planinom, ne mogu više bez tebe ostati ovamo.

Hodaću očiju uprtih u moje misli, ne gledajuć' naokolo, niti čujuć' zvuka, sam, neznan, povijen, ruku skrštenih i stislih, tužan, za me će dan postati kao noć mukla.

Niti ću gledat' zlatno nebo kad dođe veče Ni jedra daljna što klize Arfleru ka gatu, i, kad budem stigo staviću na grob tvoj cveće, božićnu grančicu zelenu i vres u cvatu.

\section{LIVRE SIXIÈME / ŠESTA KNJIGA}

I.

\section{LE PONT}

J'avais devant les yeux les ténèbres. L'abîme Qui n'a pas de rivage et qui n'a pas de cime, 
Était là, morne, immense ; et rien n’y remuait. Je me sentais perdu dans l'infini muet.

$\mathrm{Au}$ fond, à travers l'ombre, impénétrable voile, On apercevait Dieu comme une sombre étoile. Je mécriai : - Mon âme, ô mon âme ! il faudrait, Pour traverser ce gouffre où nul bord n'apparait, Et pour qu'en cette nuit jusquà ton Dieu tu marches, Bâtir un pont géant sur des millions d'arches.

Qui le pourra jamais ? Personne ! ô deuil ! effroi !

Pleure! - Un fantôme blanc se dressa devant moi Pendant que je jetais sur l'ombre un œil d'alarme, Et ce fantôme avait la forme d'une larme ;

C'était un front de vierge avec des mains d'enfant ; Il ressemblait au lys que la blancheur défend ;

Ses mains en se joignant faisaient de la lumière.

Il me montra l'abîme où va toute poussière, Si profond, que jamais un écho n'y répond ; Et me dit : - Si tu veux je bâtirai le pont.

Vers ce pâle inconnu je levai ma paupière.

- Quel est ton nom ? lui dis-je. Il me dit : - La prière.

\section{MOST}

Pred očima mojima bejahu tmine. Ambis

U kojem nema obale, ne uzdiže se vis, Jedino on, mračan i prostran, gde kretnje staju. Osećah se izgubljeno u nemom beskraju. Duboko dole, kroz senku, neprobojan veo, Naziraše se Bog kao tamna zvezda ceo. Ja kriknuh: - Dušo moja, o, dušo moja! Treba, Da bi prešla ponor gde kraj niotkud ne vreba I da bi noćas ti do Boga tvog mogla stići Sagradit' most, na milion lukova ga dići. Ko bi to ikad mog'o? Niko! Avaj! O, jade! Plači! - No, duh beli preda mnom odjednom stade Dok ja prestravljen promatrah strašne seni, A duh taj beše k’o suza, činjaše se meni; Likom devojče beše, a dečje ruke ima Činjaše se ko ljiljan kojeg brani belina; Ruke se sklopiše i svetlost od njih nastade. On mi pokaza ambis u koji sav prah pade, Dubok toliko da odjek ne vraća nikako; Pa mi reče: - Izgradiću most, želiš li tako. Ka bledom neznancu podigoh tad oči svoje. - Kako se zoveš? pitah. Molitva, rekao je. 